IFN Working Paper No. 896, 2012

\title{
Entrepreneurial Innovations and Taxation
}

\section{Andreas Haufler, Pehr-Johan Norbäck and Lars Persson}




\title{
Entrepreneurial innovations and taxation ${ }^{1}$
}

\author{
Andreas Haufler \\ University of Munich and CESifo \\ Pehr-Johan Norbäck \\ Research Institute of Industrial Economics, Stockholm \\ Lars Persson \\ Research Institute of Industrial Economics, Stockholm and CEPR
}

January 2012

\footnotetext{
${ }^{1}$ Paper presented at conferences and seminars in Ann Arbor, Berlin, Frankfurt, Munich, Oxford and Stockholm. We have benefited from helpful comments and suggestions by Michael Devereux, Judith Freeman, Clemens Fuest, Volker Grossmann, Dietmar Harhoff, Magnus Henrekson, Christian Keuschnigg, Andreas Oestreicher, Marco da Rin, Martin Ruf, Mikael Stenkula and Miranda Stewart. Thanks also to Christina Lönnblad for improving the language and to Nina Öhrn for research assistance. Financial support from the Jan Wallander and Tom Hedelius' Research Foundations is gratefully acknowledged. This paper was started when the first author visited the Research Institute of Industrial Economics in Stockholm. He wishes to thank the members of the Institute for their hospitality.
} 


\begin{abstract}
Many governments promote small businesses for the dual reasons of fostering 'breakthrough' innovations and employment growth. In this paper we study the effects of tax and subsidy policies on entrepreneurs' choice of riskiness of an innovation project and on their mode of commercializing the innovation (market entry versus sale). Limited loss offset provisions in the tax system induce entrepreneurs to choose projects with too little risk and this problem arises primarily when entrepreneurs market their product themselves. When innovations reduce only the fixed costs of production this leads to a fundamental policy trade-off between the declared goals of promoting employment and innovation in small, entrepreneurial firms. When innovations reduce variable production costs, policies to promote small businesses may even be unambiguously harmful.
\end{abstract}

JEL Classification: H25, L13, M13, O3

Keywords: Entrepreneurship, Innovation, Corporate taxes, Firm growth 


\section{Introduction}

Small, entrepreneurial businesses are widely believed to bring major innovations as well as employment growth to society. This paper study how the tax and subsidy system affects these roles played by small businesses. Indeed, in the last few decades, entrepreneurship has emerged as a key issue in the policy arena. ${ }^{1}$ In the European Union, for instance, the European Commission (2008) launched the "Small Business Act for Europe" in June 2008, which explicitly recognizes the central role of small and medium-size enterprises (SMEs) in the EU economy and sets out a comprehensive policy framework for the EU and its member states. Among other measures, the Commission proposes that member states should create an environment that rewards entrepreneurship, specifically mentioning taxation in this context.

One of the main reasons for the support of entrepreneurship is the important role they play as providers of "breakthrough" inventions. Baumol (2002), for example, documents the importance of the different roles played by small entrepreneurial firms and large established firms in the innovation process in the United States, where small entrepreneurial firms create a large share of breakthrough inventions whereas large, established firms provide more routinized research and development (R\&D). ${ }^{2}$ The importance of the level of riskiness in firms' R\&D strategies and its relation to firm type is illustrated in a recent study by Henkel et al. (2010). They undertake a qualitative empirical study of the electronic design automation (EDA) industry, which is characterized by three large incumbents and numerous start-ups. The authors conclude that ".. as a stylized fact, entrants pursue more radical innovation projects than incumbents. That is, they pursue innovation projects that are both more likely to fail and, in case of success, be more valuable than those pursued by incumbents" (p. 21).

A further argument for the promotion of SMEs is their potential to create new jobs. It is an explicit goal of EU policy, for example, that innovative SMEs grow into large,

\footnotetext{
${ }^{1}$ The Economist (14th March 2009) recently published a special report on entrepreneurship, "Global Heroes", describing this phenomenon.

${ }^{2}$ Scherer and Ross (1990) list a large number of inventions made by independent innovators and state that "new entrants without a commitment to accepted technologies have been responsible for a substantial share of the really revolutionary new industrial products and processes"(p. 653). The authors refer to a large number of studies indicating the importance of entrepreneurs as providers of breakthrough inventions.
} 
globally successful companies (see European Commission, 2011, p. 16). A substantial part of the net employment growth in the SME sector comes from a small number of high-growth firms, so-called 'Gazelles', which are typically young and are represented in all industries (Henrekson and Johansson, 2010).

At the same time, a substantial share of inventions made by independent innovators is commercialized through the sale or the licensing of a patent to incumbent firms. Serrano (2010, Table 1) reports for the United States that entrepreneurs sold $17.5 \%$ of their patents during the period 1983-2001, and this share increases to $24 \%$ if the patents are quality-weighted with the number of citations received. Furthermore, a large-scale survey carried out in six EU countries suggests that an additional $10 \%$ of all patents are licensed (Giuri et al., 2007). By a related measure, Blonigen and Taylor (2000, Table 1) report that high-technology industries such as electronic and medical equipment have been responsible for a disproportionately large share of firm acquisitions in the U.S. manufacturing sector.

These observations suggest that it is important for a study of government policy towards small, innovative businesses to endogenize two principal choices made by an independent entrepreneur: $(i)$ the level of riskiness (level of breakthrough) of a given R\&D project and $(i i)$ the mode of commercializing the entrepreneurial innovation. The present study incorporates both of these choices.

Moreover, our analysis focuses on two important features of existing government tax and subsidization policies towards small businesses.

First, tax systems in all OECD countries incorporate a fundamental asymmetry as positive earnings are taxed immediately, whereas losses can only be offset against positive incomes. ${ }^{3}$ Small entrepreneurs, who are developing a single business idea, will therefore not be able claim a tax rebate when they invest in a project that turns out to be unsuccessful. In Germany, for example, restrictive loss offset provisions for entrepreneurs are regarded as one of the main obstacles for the development and growth of small, innovative businesses (EFI, 2011, p. 19). In contrast, restrictions on loss offset opportunities are less important when the project is sold to a large, incumbent firm,

\footnotetext{
${ }^{3}$ This is still true when the government tries to foster innovation by means of $R \& D$ tax credits. In this case, companies can immediately deduct all R\&D expenditures (and sometimes even more than $100 \%$ of actual expenditures), but only when there are other sources of positive income. Bloom et al. (2002) and Ernst and Spengel (2011) empirically analyze the effects of R\&D tax credits on the volume of $\mathrm{R} \& \mathrm{D}$, but do not address the choice of quality (or riskiness) of an innovation project.
} 
as the incumbent is more diversified and will likely be able to offset losses on a new investment against positive taxable profits earned in its other operations. ${ }^{4}$

Second, the existing tax and subsidy policies imply that an entrepreneur will typically face lower taxes, net of subsidies received, if she enters the product market herself, as compared to selling her innovation to an incumbent firm. One reason is that governments provide various support schemes for start-ups and small businesses that cover all stages of the firms' development and range from initial research grants to the provision of subsidized loans and state guarantees to spur firm growth. Typically, entrepreneurs can only take advantage of the entire range of support programs when they enter the market themselves. In the United States, for example, two of the main programmes to promote small businesses are the Small Business Innovation Research (SBIR) programme, which grants awards for the development of technological prototypes up to USD 850.000 per firm, and the Technological Innovation Programme (TIP), which subsidizes the commercialization of successful prototypes with up to USD 3 million for a single company project. However, the latter support scheme is available only if the SME markets the product itself, or is the leading company in a joint venture (see OECD 2010a, p. 106). ${ }^{5}$

Moreover, many start ups choose incorporation and are thus subject to corporate income taxation, whereas entrepreneurs selling out to incumbent firms are typically liable to personal income taxation on the capital gains earned. At least in Europe, corporate tax rates have fallen significantly below personal income taxes during the last decades, further increasing the attractiveness of market entry from a tax perspective. In addition, several countries support small, incorporated businesses by means of reduced corporate tax rates (see OECD, 2010b), as well as other tax breaks. ${ }^{6}$ Taken together these provisions lead to a tax and subsidy advantage for entrepreneurs who market their inventions themselves, rather than selling out to an incumbent firm.

\footnotetext{
${ }^{4}$ Mirrlees et al. (2011, p. 454) stress the argument that loss offset limitations are more important for small businesses than for larger firms. Cullen and Gordon (2007) provide empirical evidence that asymmetries in the tax treatment of profits and losses have large effects on entrepreneurial risk-taking.

${ }^{5}$ Similar programmes exist in other countries. See OECD (2010a) which lists the most important support schemes for SMEs in each OECD member state.

${ }^{6}$ See, for example, the chapter on small business taxation in the Mirrlees Review (Mirrlees at al., 2011). The report describes in detail the tax privileges enjoyed by small, incorporated business in the United Kingdom.
} 
In this paper we study how these features of existing tax and subsidy policies influence the interdependent decisions of the entrepreneur to select an R\&D project and to choose the mode of commercializing the innovation. Our analysis is based on the following four-stage model. In the first stage, the entrepreneur makes an investment and chooses among projects with different risk and return characteristics associated with developing the invention. In the second stage, before the success of the project is revealed, the investor decides to either sell her invention to one of the incumbent firms in the market, or to enter the market herself. Under entry the entrepreneur will benefit from lower taxes and additional government support, if the project is successful. If the project fails, however, the entrepreneur will not be able to claim a loss offset under market entry, whereas selling the project to an incumbent firm ensures that investment costs are always tax-deductible. In a setting with competitive bidding by incumbents this tax advantage will be reflected in a higher sales price offered to the entrepreneur. In the third stage, the uncertainty is lifted. If the investor has decided not to sell her patent, and if the invention is successful, she will enter the market. In the final stage, there is competition between all active firms in the market, with or without the entrepreneur and with one firm possibly having access to a superior technology.

The results of our analysis show that tax concessions and subsidies confined to small businesses make market entry by the entrepreneur more likely in equilibrium, but at the same induce the entrepreneur to choose an inefficiently low-risk project, in order to minimize the risk of being left with non-deductible investment outlays. In our benchmark model, where innovations reduce only the fixed costs of production, this leads to a fundamental trade-off between the goals of promoting employment and competition in technology-intensive markets, and the desire of governments to foster risky 'breakthrough' inventions. In a model extension where innovations reduce variable production costs, it is even possible that policies to promote small businesses will be directly counterproductive by reducing both the degree of innovation and the level of production and employment in the innovative sector.

Our model brings together two different strands in the literature. Firstly, there is a relatively small yet established public finance literature that analyzes the effects of taxes on various decision margins of entrepreneurs. ${ }^{7}$ Several contributions focus on the progressiveness of the personal income tax schedule as an obstacle to entrepreneurial activity

\footnotetext{
${ }^{7}$ See Henrekson and Sanandaji (2011) for a recent survey.
} 
(e.g. Gentry and Hubbard, 2000; Asoni and Sanandaji, 2009). In contrast, Gordon (1998) stresses that start-up enterprises have the option of incorporating, thus benefiting from the widespread fall in corporate tax rates over the last few decades. Cullen and Gordon (2007) empirically estimate the effects of imperfect loss offset provisions and of rate differences in personal and corporate income taxation on entrepreneurial risk taking. Fuest et al. (2002) show that the presence of a substantial positive tax gap between the personal income tax and the corporation tax is a second-best solution to the problem of asymmetric information faced by new firms. Keuschnigg and Nielsen $(2002,2004)$ focus on the effects of various tax policies when entrepreneurs face financial constraints and set up a contract with a venture capitalist under conditions of one-sided or two-sided moral hazard. Finally, Egger et al. (2009) analyze the incorporation decision of entrepreneurs and provide empirical evidence that a positive tax gap between personal and corporate tax rates favors incorporation. None of these contributions, however, incorporates a choice between different R\&D projects to be undertaken, nor the option for the entrepreneur to sell her invention to an incumbent firm.

Secondly, this paper is also related to the literature on $R \& D$ and market structure, which mainly focuses on the choice of the level of R\&D efforts. ${ }^{8}$ Several papers study the type of R\&D project undertaken by firms and entrepreneurs (e.g. Bhattacharya and Mookherjee, 1986). There is also a literature on entrepreneurship and innovations, which is summarized in Acs and Audretsch (2005), and Bianchi and Henrekson (2005). To our knowledge, the only analysis considering how the entry mode affects the type of R\&D is Färnstrand Damsgaard et al. (2010). However, this paper focuses on the interaction between entrepreneurial and incumbent innovations and abstracts from tax policies, which are central to the present study.

The remainder of the paper is organized as follows. Section 2 outlines our benchmark model, where the innovation reduces only fixed costs. In Section 3, we solve the different stages of the model and determine the equilibrium allocation in different tax regimes. Section 4 analyzes the effects of tax policy on the R\&D project choice of the entrepreneur and on her commercialization mode. Section 5 analyzes a model extension where the innovation reduces variable costs of production. Section 6 discusses several other model extensions, including the role of venture capital financing. Section 7 concludes.

\footnotetext{
${ }^{8}$ For overviews, see Reinganum (1989) and Gilbert (2006) and for specific models, see Rosen (1991) and Cabral (2003).
} 


\section{The framework}

We consider an imperfectly competitive market with $n$ identical incumbent firms. Entry costs deter further firms from entering the market, unless they have a superior technology. The focus of our analysis lies on the decisions of an independent innovator, or entrepreneur, who chooses a project with certain risk characteristics and decides whether to sell the invention or try to enter the market herself. To focus on entrepreneurs as providers of breakthrough inventions, we assume that the incumbent firms do not innovate. ${ }^{9}$ The sequence of events in our benchmark model is shown in Figure 1.

********** Figure 1 about here $* * * * * * * * * *$

In Stage 1, the entrepreneur makes a fixed monetary investment $I$ in risky R\&D, in order to develop an invention. We suppose there to be an infinite number of independent research projects that the entrepreneur may undertake, all requiring the same investment costs $I$. Hence, investment projects do not vary by the size of the investment, but by the riskiness of the chosen project. Each project (say project $k$ ) is characterized by a certain success probability $p_{k}$. Along the technological frontier, entrepreneurs face a choice between projects that have a high success probability $p_{k}$ but deliver a small reduction in fixed costs in case of success, and projects that are more risky but also have a larger payoff, if successful. Importantly, we assume that the entrepreneur is risk-neutral and thus chooses the project which maximizes the expected net payoff from the investment. ${ }^{10}$

Our benchmark model assumes that a successful invention reduces only the fixed costs of production. This assumption greatly simplifies the exposition as it implies that product market competition between all firms remains symmetric and that the product market price does not depend on the chosen project. ${ }^{11}$ To give an example, the fixed cost of producing a prototype part for a new airplane or a racing car can be reduced by small,

\footnotetext{
${ }^{9}$ See Gromb and Scharfstein (2002) and Färnstrand Damsgaard et al. (2010) for models where innovation takes place both in start-ups and in established firms.

${ }^{10}$ Hence, we eliminate the well-known effect that taxes may stimulate entrepreneurial risk-taking by making the government a silent partner in the (risky) operation (Domar and Musgrave, 1944). However, this effect is fully effective only when losses are tax-deductible. Since our analysis explicitly focuses on the limitations of loss offset provisions, the Domar-Musgrave effect is of lesser importance.

${ }^{11}$ Section 5 considers the more general case where the invention reduces variable production costs.
} 
low-risk improvements in existing technologies. A high-risk, high-return alternative is instead to develop a 3D printer which 'prints' the prototype part using titanium powder, causing virtually no waste of this precious material in the process. ${ }^{12}$

With projects differing by their degree of innovation, fixed production costs are

$$
F\left(p_{k}\right)=\bar{F}-\Gamma\left(p_{k}\right)
$$

where $\Gamma_{k}^{\prime}\left(p_{k}\right)<0, p_{k} \in(0,1)$. Omitting the project index, the expected payoff $p \Gamma(p)$ is assumed to be strictly concave in $p$. Figure 2 illustrates the payoffs of different projects in terms of expected fixed costs reductions.

$* * * * * * * * *$ Figure 2 about here $* * * * * * * * * *$

As Figure 2 shows, there is a unique project with success probability $0<\hat{p}<1$ that maximizes the expected payoff of the invention (or minimizes the expected fixed costs with the invention), given from the first-order condition

$$
\Gamma(\hat{p})+\hat{p} \Gamma^{\prime}(\hat{p})=0
$$

In the following, we will refer to an R\&D project with a risk level of $\hat{p}$ as the 'costefficient' project. It is instructive to compare the project type chosen by the entrepreneur in equilibrium with this cost-efficient project. More formally, we introduce

Definition 1: The cost-efficient project is given by $\hat{p}=\arg \max _{p} p \Gamma(p)$.

In Stage 2, after investment $I$ has been made and R\&D project $k$ has been chosen, the entrepreneur can either sell her invention to one of the incumbents or decide to market the invention herself. If the entrepreneur decides to sell her project, the acquiring incumbent will replace his initial technology with the innovative one. In this case, there will thus still be $n$ firms in the market, though one firm (the acquirer of the innovation) may have a superior technology. In the case where the entrepreneur decides to enter the market, there will be $(n+1)$ firms in the market, once more with one firm (the entrepreneur herself) having a possibly superior technology, in the sense of facing lower fixed production costs.

The entrepreneur's decision of whether to enter the market or sell the innovation to one of the incumbent firms is affected by tax considerations. We denote by $t^{e}$ the

\footnotetext{
${ }^{12}$ See the article "The printed world" in The Economist, 10 February 2011.
} 
effective tax rate, net of subsidies received, faced by the entrepreneur when she decides to enter the market, whereas $\tau$ gives the tax rate that is applicable on the income she receives when selling the project to an incumbent firm. For the reasons given in the introduction, our main analysis is based on a policy setting where $t^{e} \leq \tau$ and there is a tax/subsidy advantage from market entry. ${ }^{13}$

Most importantly, the tax advantage from market entry lies in the additional subsidies received in the marketing stage, which are granted only when the entrepreneur enters the market herself. Moreover, the tax treatment of entrepreneurs is also likely to differ depending on their mode of commercializing the innovation. We assume that entrepreneurs producing for market entry will incorporate their business and are thus subject to the corporate income tax. ${ }^{14}$ In contrast, entrepreneur producing for sale will remain unincorporated and are thus subject to personal income taxation. In general, it is difficult to compare the taxation of incorporated and unincorporated businesses, as this comparison depends not only on corporate and personal income tax schedules but also on a number of other country-specific characteristics. In Europe, however, corporate tax rates have fallen particularly strongly over the last decades, probably as a result of intense tax competition (see Devereux et al., 2008). Moreover, all European countries operate some form of double taxation relief under the corporate income tax and several countries have special, reduced corporate tax rates for small businesses. In this region, therefore, it is likely that the market entry of entrepreneurs is tax-favored over the alternative of project sale, even though - in some countries - reduced capital gains taxes are applicable for the latter. ${ }^{15}$

\footnotetext{
${ }^{13}$ In Section 6.3 we analyze an alternative setting where tax rates under both commercialization modes are identical, but the sale to an incumbent is subject to transaction costs.

${ }^{14}$ According to de Mooij and Nicodème (2008, Table 1), roughly $35 \%$ of all businesses in the European Union were incorporated during the period 1998-2003, with wide divergences across countries. Interestingly, however, the average share of incorporation was slightly higher among new firms than among established firms (36.8\% vs. 35.7\%), despite the fact that established firms are, on average, much larger. Moreover, selection effects can be clearly observed in the data. In Sweden, for example, only $25 \%$ of all firms which started up in 2005 and were still active in 2008 were incorporated (of a total of 29795 start-ups). Among the incorporated start-ups, however, about $72 \%$ were high-growth firms, as compared to $34 \%$ high-growth firms in other groups. This indicates that successful innovators are substantially more likely to use incorporation (see Tillväxtanalys, 2010).

${ }^{15}$ See de Mooij and Nicodème (2008, Table 4), who calculate that the average corporate income tax rate for small businesses in a sample of 20 European countries was $24 \%$ in 2003, as compared to an average of the top personal income tax rate of almost $43 \%$. The authors provide evidence that this tax
} 
In Stage 3, the uncertainty is revealed and it turns out whether the innovation is successful or not. If the entrepreneur has not sold her invention, she is free to enter the market at this stage. However, due to entry costs and fixed costs of production, entering the market will only be profitable when the innovation is successful (i.e. fixed production costs are low). If the project fails, the entrepreneur will not enter the market and she will lose all investment costs.

In Stage 4, oligopolistic product market competition occurs between either $n$ or $(n+1)$ firms, depending on the commercialization decision of the entrepreneur in Stage 2 and (in case of market entry) on the success of the project in Stage 3. Equilibrium profits are paid out and taxes are collected on all income.

\section{Equilibrium project choice and mode of commer- cialization}

\subsection{Stage 4: Product market interaction}

We solve the model by backward induction and start with the interaction of firms in the product market. Let the set of firms in the industry be $\mathcal{J}=e \cup \mathcal{I}$, where $\mathcal{I}=\left\{i_{1}, i_{2} \ldots i_{n}\right\}$ is the set of identical incumbent firms and $e$ is the entrepreneur. The owner of the invention is denoted by $m \in \mathcal{J}$. In the product market interaction, firm $j$ chooses an action $x_{j} \in R^{+}$to maximize its product market profit net of fixed costs, $\pi_{j}\left(x_{j}, \mathbf{x}_{-j}, m\right)-F_{j}$. This depends on its own and its rivals' market actions, $x_{j}$ and $\mathbf{x}_{-j}$, the identity of the owner of the invention, $m$, and the fixed cost $F_{j}$ to serve the market. If firm $j$ owns the invention, and if the project is successful, its fixed cost is $F(p)$. All other firms have fixed production costs $\bar{F}$. This is also the fixed cost of the firm possessing the invention, in case the invention has failed.

We consider firm $j$ 's action $x_{j}$ as setting either a quantity or a price. We assume that a unique Nash equilibrium $\mathbf{x}^{*}(m)=\left\{x_{j}^{*}(m), x_{-j}^{*}(m)\right\}$ exists at this stage, which is defined as:

$$
\left(1-t^{m}\right) \pi_{j}\left(x_{j}^{*}, x_{-j}^{*}, m\right) \geq\left(1-t^{m}\right) \pi_{j}\left(x_{j}, x_{-j}^{*}, m\right), \quad \forall x_{j} \in R^{+}
$$

wedge plays a significant role in explaining the rising share of incorporated firms in many European countries and the accompanying shift in tax revenue from the personal to the corporate income tax. 
where $t^{m}$ is the tax rate on each firm's profits, which may differ for incumbents $(m=i)$ and for the entrepreneur $(m=e)$. We assume product market profits to be positive. From (3), we can define a reduced-form product market profit (before deduction of fixed costs) for a firm $j$, taking as given ownership $m$ :

$$
\pi_{j}(m) \equiv \pi_{j}\left[x_{j}^{*}(m), x_{-j}^{*}(m), m\right]
$$

Since incumbents $i_{1}, i_{2}, \ldots, i_{n}$ are symmetric before the acquisition takes place, we need only distinguish between two types of ownership of the invention: entrepreneurial ownership $(m=e)$ and incumbent ownership $(m=i)$. Moreover, since the innovation affects only fixed production costs, the product market profit before deduction of fixed costs and taxes is always the same for all active firms in our benchmark model. Hence, there are only two possible levels of such profits: $\pi(i)$ is the profit of each incumbent when the entrepreneur does not enter the market, whereas $\pi(e)$ is the product market profit of incumbents and the entrepreneur in case of entry.

We assume that market entry by the entrepreneur will reduce the profit of each producer due to stronger competition, i.e $\pi(i)>\pi(e)$. This assumption is met in standard models of imperfect competition, such as the oligopoly model of quantity competition in a homogeneous good, or the model of price competition with differentiated products.

For later use in our welfare analysis (Section 4.2), let us also make the assumption that labor is a primary input in the production of firm $j^{\prime} s$ product and in its fixed cost. Normalizing the wage to unity and noting symmetry, it will then be useful to define the reduced-form employment in production as $l_{j}(m) \equiv l_{j}\left(q_{j}\left(\mathbf{x}^{*}(m)\right)\right.$, where $q_{j}\left(\mathbf{x}^{*}(m)\right)$ is the level of output in firm $j$. If we assume Cournot competition, then $x_{j}^{*}(m)=q_{j}^{*}(m)$ and $l_{j}(m) \equiv l_{j}\left(q_{j}^{*}(m)\right)+F_{j}$. Under Bertrand competition $x_{j}^{*}(m)=$ $P_{j}^{*}(m)$ and $q_{j}^{*}\left(\mathbf{P}^{*}(m)\right)$, where $\mathbf{P}^{*}(m)$ is the vector of prices in the Nash-equilibrium. The reduced-form labor demand is then $l_{j}(m) \equiv l_{j}\left(q_{j}^{*}\left(\mathbf{P}^{*}(m)\right)\right)+F_{j}$.

\subsection{Stage 3: Uncertainty revealed}

At this stage, it is revealed whether the innovation turns out to be successful or not, where 'success' can either be interpreted in a technological or in a commercial sense. For example, this stage may describe the results of mechanical or medical tests, which determine whether a new, cost-saving technology is feasible. For other innovations, 
it may be revealed at this stage whether a small-scale market test shows a sufficient acceptance among prospective buyers to make the introduction of the new technology commercially viable.

If the innovation is successful, the superiority of the new product over the existing ones is reflected in reduced fixed costs of $F(p)<\bar{F}$ from (1). Under failure, the invention does not reduce the fixed costs for the owner and fixed production costs remain at $\bar{F}$. If the owner of the invention is an incumbent firm at this stage, then the success or failure of the innovation has no consequences other than affecting the profits of the acquiring firm. In contrast, if the entrepreneur decided in the previous stage not to sell the invention, the success or failure of the project will affect her decision to enter the market at this stage. We assume that there are entry costs $G$ to the imperfectly competitive market, which are sufficiently high to render market entry unprofitable in case of project failure. To simplify the algebra, it proves convenient to assume that the profits from market entry without an improved technology are just equal to zero, and market entry occurs only when profits are strictly positive. ${ }^{16}$ This is formalized in:

Assumption A1: When the innovation fails, net profits from entry are zero, $\pi(e)-$ $\bar{F}-G=0$, and the entrepreneur does not enter. When the innovation is successful, the entrepreneur receives positive net profits equal to $\pi(e)-[\bar{F}-\Gamma(p)]-G=$ $\Gamma(p)>0$ and enters the market.

Assumption A1 implies that there will be $(n+1)$ firms in the final stage of the game only if the entrepreneur does not sell the invention in Stage 2, and if the project is successful. The first part in Assumption A1 also ensures that the initial market structure is stable, since no competitor can profitably enter the market given the existing technology with fixed costs $\bar{F}$ and entry cost $G$.

In the case of project failure, the entrepreneur's initial investment costs $I$ are lost entirely. To protect the income tax base and prevent fraud, existing tax codes allow the deductibility of expenses only in combination with positive income, but do not pay out negative taxes to the taxable entity in case of a loss. ${ }^{17}$ Moreover, in the case of

\footnotetext{
${ }^{16}$ In essence, this is a free entry condition that will be approximated when the number of incumbents is not too low. It implies that there is no 'entry hurdle' that would reduce the value of the innovation $(\Gamma)$ for the entrepreneur in case of market entry.

${ }^{17}$ Our static model abstracts from the possibility that the entrepreneur can carry forward the loss
} 
project failure it is also not possible for the entrepreneur to sell her unused tax credit to one of the incumbents. The reason is that in this case the tax authorities will not accept a link between an incumbent's positive income from existing assets and the losses incurred by the R\&D project.

Note, finally, that our sequence of events implies that the entrepreneur cannot sell her firm after the uncertainty has been lifted. In Section 6.2 we will relax this assumption and show that if a sale has not already occurred in Stage 2, there will also be no postuncertainty sale in Stage 3, no matter whether the project turns out to be successful or not.

\subsection{Stage 2: Commercialization}

In Stage 2, there is an entry-acquisition game where the entrepreneur can decide whether to sell the invention to one of the incumbents or enter the market at the fixed cost $G$, knowing that this is profitable only when the project is successful. The commercialization process is depicted as an auction where $n$ incumbents simultaneously post bids and the entrepreneur then either accepts or rejects these bids. If the entrepreneur rejects all bids, she will try to enter the market herself. Each incumbent announces a bid, $b_{i}$, for the invention and $\mathbf{b}=\left(b_{1}, . . b_{i} . ., b_{n}\right) \in R^{n}$ is the vector of these bids. Following the announcement of $\mathbf{b}$, the invention may be sold to one of the incumbents at the bid price, or remain in the ownership of entrepreneur $e$. If more than one bid is accepted, the bidder with the highest bid obtains the invention. If there is more than one incumbent with such a bid, each such incumbent obtains the invention with equal probability. The acquisition game is solved for Nash equilibria in undominated pure strategies. There is a smallest amount, $\varepsilon$, chosen such that all inequalities are preserved if $\varepsilon$ is added or subtracted. To solve the commercialization game, it will be useful to define $\Delta_{e}(S)$ as the net gain for the entrepreneur of selling the invention at a sales price $S$, over the alternative of market entry.

As discussed in Section 2, the entrepreneur faces the effective tax rate $t^{e}$ in case of market entry. We assume that this tax is levied at a proportional rate. Investment costs can be deducted from the tax base when there is positive income, but tax credits

for a certain number of years. Empirical evidence suggests that failed start-ups are rarely able to use loss carry forward provisions in subsequent years. See Auerbach and Altshuler (1990) and Auerbach (2006) for empirical evidence documenting the importance of unused tax credits among U.S. firms. 
are not paid out when the project fails and the entrepreneur's income is thus negative. If the entrepreneur produces for sale, she will be taxed at the tax rate $\tau$ on her capital gains, which are defined as the excess of the sales price over the investment costs. In this case the acquiring incumbent can always deduct the sales price from its positive operating profit, irrespective of whether the invention is successful or not. With these specifications and using Assumption A1, the entrepreneur's net gain from selling the invention at price $S$ over the alternative of market entry is

$$
\Delta_{e}(S)=\underbrace{S-\tau(S-I)}_{\text {Net profit from sale }}-[\underbrace{p \Gamma(p)-p t^{e}[\Gamma(p)-I]}_{\text {Net expected profit from entry }}] .
$$

From (5), let the reservation price of the entrepreneur be $v_{e}=\min S$, s.t $\Delta_{e}(S) \geq 0$. That is, $v_{e}$ is the minimum price $S$ at which the entrepreneur is willing to sell. Solving for $\Delta_{e}(S)=0$, we get:

$$
v_{e}(p)=\frac{\left(1-t^{e}\right)}{(1-\tau)}\left[p \Gamma(p)-\frac{\left(\tau-p t^{e}\right)}{\left(1-t^{e}\right)} I\right] .
$$

The reservation price $v_{e}$ in (6) gives the entrepreneur's product market profits, net of the effective corporate taxes $t^{e}$ that she must pay under market entry, but grossed up by the personal income tax $\tau$ that is due under sale.

Next, we turn to the incumbent firms' valuations of the invention. When an incumbent acquires the invention, it is certain that there will only be $n$ firms in the market in the final stage and hence its reduced product market profit is always given by $\pi(i)$. When not acquiring the entrepreneurial firm, the invention can either remain in the hands of the entrepreneur $(m=e)$ or it can be acquired by a rival incumbent firm $(m=i)$. This difference will affect the profits of the non-acquiring incumbent if the invention is successful, because only in this case will the entrepreneur decide to enter the market. When the invention fails, the profit of each incumbent will always be $\pi(i)$ in the product market stage, irrespective of the ownership of the invention. The profits of incumbent firms are taxed at the rate $t^{i} .{ }^{18}$ Finally, as discussed above, the sales price $S$ is always tax-deductible for the acquiring firm. ${ }^{19}$ Denoting the net gain for

\footnotetext{
${ }^{18}$ The tax rate $t^{i}$ will typically exceed the tax rate $t^{e}$ faced by the entrepreneur under market entry, because incumbents are not eligible for reduced tax rates or support schemes tied to small businesses.

${ }^{19}$ Our static model assumes that the full sales price $S$ is immediately tax-deductible for the acquiring firm. In actual tax law, the sales price is treated like an investment that can only be deducted pro-rata over several years. Hence, in a dynamic model the present value of being able to deduct $S$ would be somewhat lower for the acquiring firm, but this would not qualitatively alter our results.
} 
an incumbent firm of acquiring the entrepreneur's invention at a certain price $S$ by $\Delta_{i m}(S)$ for $m=e, i$ then yields

$$
\begin{aligned}
\Delta_{i l}(S)= & \underbrace{p\left(1-t^{i}\right)[\underbrace{\pi(i)-(\bar{F}-\Gamma(p))-S}_{\text {Profit with project }}-\underbrace{(\pi(m)-\bar{F})}_{\text {Profit without project }}]}_{\text {Net expected value from a successful innovation }} \\
& \underbrace{+(1-p)\left(1-t^{i}\right)[\underbrace{\pi(i)-\bar{F}-S}_{\text {Profit with project }}-\underbrace{(\pi(i)-\bar{F})}_{\text {Profit without project }}]}_{\text {Net expected value from an unsuccessful innovation }} \\
= & \left(1-t^{i}\right)\{-S+p \Gamma(p)+p[\pi(i)-\pi(m)]\},
\end{aligned}
$$

where we have expanded the right-hand side of $(7)$ with $p \pi(i)$ to arrive at the final expression for $\Delta_{i l}(S)$.

From (7), we can define an incumbent firm's valuation as $v_{i m} \equiv \max S$, s.t $\Delta_{i m}(S) \geq 0$. Solving for $\Delta_{i m}(S)=0$ gives $v_{i m}=p \Gamma(p)+p[\pi(i)-\pi(m)]$ as the maximum price $S$ at which an incumbent firm is willing to buy the entrepreneur's invention. Incumbent firms thus have two valuations: The first is a takeover valuation, which is an incumbent firm's value of acquiring the invention when this would otherwise remain in the hands of the entrepreneur. In this case $m=e$ and

$$
v_{i e}(p)=p \Gamma(p)+p[\pi(i)-\pi(e)]
$$

where $p \Gamma(p)$ is the expected fixed costs savings of the invention and $p[\pi(i)-\pi(e)]>0$ is the expected increase in product market profits when the entrepreneur is prevented from entering the market.

The second valuation is a competitive valuation, which is an incumbent firm's value of acquiring the invention when a rival incumbent firm would otherwise obtain it. Then $m=i$ and

$$
v_{i i}(p)=p \Gamma(p)
$$

Since the invention only affects fixed production costs, the preemptive value is in this case simply the expected fixed costs savings of the invention. Comparing (8) and (9), it is obvious that $v_{i e}>v_{i i}$ since $\pi(i)>\pi(e)$. This describes the concentration effect of an acquisition when entry by the entrepreneur is prevented. Finally, note that the 
incumbent firms' valuations are unaffected by their profit tax rate $t^{i}$, because competitive bidding ensures that the equilibrium sales price will equal the expected increase in profits from acquiring the invention.

We can now proceed to solve for the Equilibrium Ownership Structure (EOS). Since incumbents are symmetric and $v_{i e}>v_{i i}$ always holds, there are three different regimes that we need to consider. These are summarized in Table 1. The following lemma can then be stated:

Lemma 1 The equilibrium ownership of the invention $m^{*}$ and the acquisition price $S^{*}$ are described in Table 1.

Proof: See the Appendix.

Table 1: The equilibrium ownership structure and the acquisition price

\begin{tabular}{cccc}
\hline Regime & Definition & Ownership & Acquisition price \\
\hline$R 1:$ & $v_{e}(p)>v_{i e}(p)>v_{i i}(p)$ & $m^{*}=e$ & - \\
$R 2:$ & $v_{i e}(p)>v_{e}(p)>v_{i i}(p)$ & $m^{*}=i$ & $S^{*}=v_{e}(p)$ \\
$R 3:$ & $v_{i e}(p)>v_{i i}(p)>v_{e}(p)$ & $m^{*}=i$ & $S^{*}=v_{i i}(p)$ \\
\hline
\end{tabular}

Table 1 describes the equilibrium mode of commercialization as a function of the R\&D project chosen by the entrepreneur in the first stage, characterized by its success probability $p$. In Regime 1 (R1 for short), the expected profit from entering the market is higher for the entrepreneur than selling the invention to one of the incumbents. In Regime 2 the entrepreneur will sell her invention, but the sales price will be determined by the reservation price $v_{e}$ of the entrepreneur. This is because if one incumbent firm bids the reservation price, all other incumbents will only be willing to bid the competitive valuation, which is below $v_{e}$ in this regime. Hence, the equilibrium bid equals the reservation price of the entrepreneur. In Regime 3, the invention is also sold in equilibrium, but the price equals the competitive valuation $v_{i i}$. Since all incumbents are simultaneously willing to bid this price, it is also the equilibrium sales price in Regime 3, where one of the incumbents is drawn as the acquirer.

Note that the gains from an entry deterring acquisition in Regime 2 are unevenly distributed among incumbents, as the acquiring incumbent bears the cost of the entry de- 
terrence while the other firms can free-ride on the acquisition. This raises the possibility of coordination failures among incumbents, if $v_{i e}(p)>v_{e}(p)>v_{i i}(p)$. If a coordination failure occurs, the entrepreneur may enter the market even though $v_{i e}(p)>v_{e}(p)$. This can be shown by extending the acquisition auction to allow for mixed strategy equilibria. In a mixed strategy equilibrium incumbents can bid $v_{e}(p)$ with some probability. There are then two possible outcomes. In the first, at least one incumbent bids $v_{e}(p)$ and an entry deterring acquisition takes place. In the second, no incumbent bids for the project and the entrepreneur enters the market.

\subsection{Stage 1: Project choice by the entrepreneur}

In this section, we solve for the equilibrium project selected by the entrepreneur, given that she anticipates the mode of commercialization in the second stage of the game. Since the rewards differ across regimes, the equilibrium project chosen by the entrepreneur has to be determined independently for each regime. Noting that investment costs $I$ are independent of project choice, the entrepreneur simply chooses the project that maximizes the net reward in each regime. From Lemma 1 the net reward for the entrepreneur, denoted by $\Omega^{*}(p)$, can be written as

$$
\Omega^{*}(p)=\left\{\begin{array}{cc}
\left(1-t^{e}\right) p \Gamma-\left(1-p t^{e}\right) I \equiv(1-\tau)\left[v_{e}(p)-I\right] & \text { in R1 } \\
(1-\tau)\left[v_{e}(p)-I\right] & \text { in R2 } \\
(1-\tau)\left[v_{i i}(p)-I\right] & \text { in R3 }
\end{array}\right.
$$

Note that in Regime 1 the net reward is the entrepreneur's net expected profit from entry [see eq. (5)] less the investment costs $I$. By the construction of the reservation price $v_{e}$ in (6), this is equal to the net reward in the (hypothetical) situation where the entrepreneur receives a sales price $v_{e}$ and pays personal income taxes on the excess of this sales price over the investment costs $I$. This is also how the net reward is calculated in Regimes 2 and 3, where the sale actually takes place.

To derive the equilibrium project choices we start with Regime 3, where the entrepreneur sells her invention at price $S^{*}=v_{i i}(p)$. In this regime, the net reward is maximized by incorporating the corporate tax treatment of the incumbent firms. From eq. (10), the entrepreneur will choose the project $p_{S}^{*}=\arg \max _{p}(1-\tau)\left(v_{i i}(p)-I\right)=\arg \max _{p} v_{i i}(p)$, where the subscript $S$ stands for the project choice in the sales Regime 3 . The associated first-order condition is:

$$
\Gamma\left(p_{S}^{*}\right)+p_{S}^{*} \Gamma^{\prime}\left(p_{S}^{*}\right)=0
$$


Since incumbents can fully deduct the investment costs from their taxable profits, the corporation tax is a lump-sum instrument in this regime. From the perspective of the entrepreneur, the sales price is therefore maximized by choosing the project that maximizes the expected fixed cost reduction, as given by $\hat{p}$ in equation (2).

Next, we consider the optimal project choice in Regimes 1 and 2. In Regime 1 the entrepreneur enters the market herself, whereas in Regime 2 she sells the invention, but the sales price is determined by her reservation price $v_{e}$ (the expected profits in case of entry). In both regimes, the net reward $\Omega^{*}=(1-\tau)\left[v_{e}(p)-I\right]$ is thus maximized by incorporating the loss offset provisions that apply to the entrepreneur. The optimal project is given from $p_{E}^{*}=\arg \max _{p}(1-\tau)\left[v_{e}(p)-I\right]=\arg \max _{p} v_{e}(p)$, where the project choice is denoted by the subscript $E$. The associated first-order condition is

$$
\Gamma\left(p_{E}^{*}\right)+p_{E}^{*} \Gamma^{\prime}\left(p_{E}^{*}\right)=-\frac{t^{e}}{\left(1-t^{e}\right)} I .
$$

The negative term on the right-hand side of (12) shows that in Regimes 1 and 2, the entrepreneur will not choose the cost-efficient project $\hat{p}$ defined in (2). The distortion arises because the entrepreneur cannot deduct her investment costs from tax in the case of project failure. This will induce her to choose a project with an inefficiently low level of risk. This effect is the stronger, the higher is the effective tax rate $t^{e}$ faced by the entrepreneur in case of market entry.

\section{The effects of tax policy}

\subsection{Effects on project choice and commercialization mode}

In this section, we analyze how the system of taxing and subsidizing entrepreneurial incomes affects the mode of commercialization and the project choice by the entrepreneur. We focus on exogenous variations in the effective rate of corporate profit taxation that the entrepreneur faces in case of market entry. To simplify the notation, we drop the superscript $e$ for this tax rate from here on, so that $t \equiv t^{e}$. In this analysis, we hold constant the personal income tax rate $\tau$, which is levied in the case of project sale. To ensure that all possible regimes derived in the preceding section can occur, we assume that market entry must be the entrepreneur's preferred mode of commercialization when $t=0$. Effectively, this requires that $\tau$ must not be too low, relative to the entry costs $G$. This is formally stated in: 
Assumption A2: When $t=0$, the entrepreneur's reservation value exceeds the incumbents' takeover valuation, i.e. $\left.v_{e}\left(p_{E}^{*}\right)\right|_{t=0}>\left.v_{i e}\left(p_{E}^{*}\right)\right|_{t=0}$.

On the other hand, if the entrepreneur faced the same tax rate under the two modes of commercialization, she would always choose to sell her invention to an incumbent firm. This is seen from setting $\tau=t$ in (6), yielding

$$
\left.v_{e}(p)\right|_{t=\tau}=p \Gamma-\frac{t(1-p)}{(1-t)} I<v_{i i}=p \Gamma, \forall p \in[0,1]
$$

In this case, the reservation value of market entry for the entrepreneur falls short of the competitive valuation by incumbents. This implies that, in equilibrium, the entrepreneur sells her invention at the price $v_{i i}$. By selling the invention, the entrepreneur saves the additional expected tax payments that result from the inability to deduct the investment costs in case of project failure. Since selling the invention yields at least the expected payoff of the invention in the competitive bidding auction modeled here, there are no offsetting benefits from market entry when tax rates are equal under the two alternative modes of commercialization.

In the following, we therefore consider effective corporate tax rates $t$ (net of government subsidies) for the entrepreneur, which range from zero to the personal income tax rate $\tau$. From our discussion in Section 2, raising $t$ towards $\tau$ is equivalent to a policy that reduces tax concessions and specific subsidies exclusively granted to small firms. To proceed, we introduce two critical corporate tax rates $t^{E D}$ and $t^{C}$, where the valuation of the project by the entrepreneur equals the entry deterring (or takeover) valuation and the competitive valuation by the incumbents, respectively.

Definition 2: Let $t^{E D}$ be defined from $\left.v_{e}\left(p_{E}^{*}\right)\right|_{t=t^{E D}}=\left.v_{i e}\left(p_{E}^{*}\right)\right|_{t=t^{E D}}$, and let $t^{C}$ be defined from $\left.v_{e}\left(p_{E}^{*}\right)\right|_{t=t^{C}}=\left.v_{i i}\left(p_{E}^{*}\right)\right|_{t=t^{C}}$.

The following proposition describes how the commercialization mode depends on the tax rate.

Proposition 1 Assume that $t^{E D}$ and $t^{C}$ exist. Then: (i) commercialization by entry (Regime 1) occurs, if the effective rate of profit taxation is low, $t \in\left[0, t^{E D}\right)$; (ii) commercialization by sale occurs at the sales price $S^{*}=v_{e}$ (Regime 2), if the profit tax rate is in the intermediate range $t \in\left[t^{E D}, t^{C}\right.$ ); (iii) commercialization by sale occurs at the sales price $S^{*}=v_{i i}$ (Regime 3), if the profit tax rate is sufficiently high, $t \in\left[t^{C}, 1\right]$. 
Proposition 1, in turn, leads to a proposition describing how project choice depends on the tax rate.

Proposition 2 Suppose that Proposition 1 holds. Then: (i) for low profit tax rates $t<t^{C}$, the entrepreneur chooses a project with a higher success probability than the cost-efficient one, $p^{\text {opt }}=p_{E}^{*}>\hat{p}$; (ii) for sufficiently high profit tax rates $t \geq t^{C}$, the entrepreneur's project choice is efficient, $p^{o p t}=p_{S}^{*}=\hat{p}$.

Project choice and taxes. Let us first prove Proposition 2. Consider the effects of a change in $t$ on project choice, taking as given how taxes affect the commercialization mode. Implicitly differentiating (11) in Regime 3 and (12) in Regimes 1 and 2 yields

$$
\frac{d p^{o p t}}{d t}=\left\{\begin{array}{cl}
\frac{-I}{\left(2 \Gamma^{\prime}+p_{E}^{*} \Gamma^{\prime \prime}\right)(1-t)^{2}}>0 & \text { in } \mathrm{R} 1, \mathrm{R} 2 \\
0 & \text { in R3 }
\end{array}\right.
$$

where $2 \Gamma^{\prime}+p_{E}^{*} \Gamma^{\prime \prime}<0$ follows from the assumption that $p \Gamma(p)$ is strictly concave.

Figure 3 about here

The upper panel of Figure 3 illustrates the relationship between the effective corporate tax rate $t$ and the equilibrium project choice, as characterized by the success probability $p$. From Proposition 1 (and thus anticipating the proof below), Regime 1 arises for low effective corporate tax rates $t<t^{E D}$, Regime 2 arises for intermediate tax rates $t^{E D}<t<t^{C}$, and Regime 3 arises for high tax rates $t>t^{C}$. To interpret panel (i) of Figure 3, note that the negative effect on the RHS of (12) is absent for $t=0$ and the chosen project is therefore cost-efficient. As $t$ is increased, the success probability of the equilibrium project continuously rises throughout Regimes 1 and 2 [cf. eq. (14)], because the rise in $t$ makes the deductibility of the initial investment outlays more valuable, and this deductibility can only be used when the project is successful.

In Regime 3, the entrepreneur sells the invention at price $S^{*}=v_{i i}$ and the optimal project choice is independent of the effective profit tax rate, $d p_{S}^{*} / d t=0$. Overall, therefore, the equilibrium level of $p$ adjusts in a non-monotonous way to the profit tax rate $t$, rising continuously throughout Regimes 1 and 2 and then dropping back to the efficient level $p_{S}^{*}=\hat{p}$ at the switch to Regime 3 . 
Commercialization mode and taxes. Let us now prove Proposition 1. Panel (iii) of Figure 3 depicts the valuations $v_{e}\left(p^{o p t}\right), v_{i e}\left(p^{o p t}\right)$ and $v_{i i}\left(p^{o p t}\right)$ as functions of the profit tax rate $t$. All valuations incorporate the optimal project choice $p^{o p t}$, which is given by

$$
p^{o p t}=\left\{\begin{array}{c}
p_{E}^{*}, t \in\left[0, t^{C}\right), \\
p_{S}^{*}, t \in\left[t^{C}, 1\right] .
\end{array}\right.
$$

To see how the different valuations depend on the profit tax rate, we need to determine both the direct effect of $t$ and the indirect effect through the optimal project choice $p^{\text {opt }}$ in (15):

$$
\frac{d v_{r}\left(p^{o p t}\right)}{d t}=\underbrace{\frac{\partial v_{r}}{\partial t}}_{\text {direct effect }}+\underbrace{\frac{\partial v_{r}}{\partial p} \frac{d p^{o p t}}{d t}}_{\text {indirect effect }} \quad \forall r \in\{e, i e, i i\} .
$$

We start by evaluating eq. (16) for the entrepreneur's reservation price $v_{e}$, as given in (6). In Regimes 1 and 2, which arise for $t<t^{C}$, the indirect effect in (16) is zero due to the envelope theorem, $\partial v_{e} / \partial p=0$. In Regime 3, which occurs for $t>t^{C}$, the indirect effect is also zero because $d p^{o p t} / d t=0$ from eqs. (15) and (11). Hence, within each regime, only the direct effect $\partial v_{e} / \partial t$ is operative. Therefore:

$$
\frac{\partial v_{e}\left(p^{o p t}\right)}{\partial t}=\frac{-p^{o p t}}{(1-\tau)}\left[\Gamma\left(p^{o p t}\right)-I\right]<0,
$$

where the term in the squared bracket is positive since the entrepreneur must earn a positive net reward on her investment when the project is successful. It follows that within each regime the entrepreneur's reservation price $v_{e}\left(p^{o p t}\right)$ is monotonously falling in the profit tax rate $t$. This can be seen in panel (iii) of Figure $3 .^{20}$

Let us now turn to the valuations of incumbents, $v_{i m}$. The direct effect of $t$ on both $v_{i e}$ and $v_{i i}$ is zero from (8) and (9), so we must have $\partial v_{i m} / \partial t=0$ in eq. (16). Then, note that the indirect effect in eq. (16) consists of the induced changes in project choice, as given in (14), and the incumbents' valuation of these changes, $\partial v_{i m} / \partial p .{ }^{21}$ The latter are relevant only in Regimes 1 and 2 and are given by

$$
\frac{\partial v_{i e}}{\partial p}=\Gamma+p_{E}^{*} \Gamma^{\prime}+\pi(i)-\pi(e), \quad \frac{\partial v_{i i}}{\partial p}=\Gamma+p_{E}^{*} \Gamma^{\prime} .
$$

\footnotetext{
${ }^{20}$ Note that the envelope theorem can only be used in Regimes 1 and 2 , where the optimal project chosen by the entrepreneur is based on the maximization of $v_{e}$. Hence, if the project choice changes discretely at the tax rate $t^{C}$, the value of $v_{e}$ may exhibit a jump at this point.

${ }^{21}$ The envelope theorem can not be applied to determine the effect of $t$ on the incumbents' valuations, because the project is not chosen to maximize $v_{i e}$ or $v_{i i}$ in Regimes 1 and 2 .
} 
For $t<t^{C}$, increases in the tax rate $t$ (and thus in $p$ ) have a negative effect on $v_{i i}$ and an ambiguous effect on $v_{i e}$. At the switch to Regime 3 at $t=t^{C}$, there is a jump in the valuation of incumbents due to the discrete change in optimal project choice from eq. (15). Thus, as shown by panel (iii) of Figure 3, the competitive valuation $v_{i i}\left(p^{o p t}\right)$ is decreasing in $t$ until the switch to Regime 3 at $t=t^{C}$, where $v_{i i}$ jumps up to $v_{i i}\left(p_{S}^{*}\right)>v_{i i}\left(p_{E}^{*}\right)$. The takeover valuation $v_{i e}\left(p^{o p t}\right)$ has a similar overall pattern and will also exhibit a jump at $t=t^{C}$.

The equilibrium commercialization pattern is shown by panel (ii) of Figure 3. When the corporate tax rate is low, $t \in\left(0, t^{E D}\right)$, the entry value $v_{e}$ exceeds the incumbents' takeover valuation $v_{i e}$. This leads to an equilibrium in Regime 1 with the entrepreneur retaining the ownership of her invention and entering the market in case the invention succeeds. As the profit tax rate increases, it reaches the first critical value, denoted $t^{E D}$, where the entrepreneur's reservation value equals the takeover valuation of the incumbents. At $t=t^{E D}$, the equilibrium switches to Regime 2 with an entry deterring acquisition taking place at the acquisition price $S^{*}=v_{e}$. Other incumbents will not preempt a rival's acquisition in the range $t \in\left[t^{E D}, t^{C}\right)$, since the net value of preemption is negative, $v_{i i}-v_{e}<0$. As $t$ rises further, it reaches the second critical level, denoted $t=t^{C}$, where the entrepreneur's reservation value falls to the competitive valuation of the incumbent firms. This induces a bidding war between incumbents and results in Regime 3 where the sales price of the invention is fixed by the competitive valuation of the incumbents. Further increases in $t$ continue to reduce the entry value of the entrepreneur, which falls to zero at $t=1$.

To summarize, government policies that reduce the effective profit taxation of small businesses by granting reduced tax rates and various subsidies encourage market entry by entrepreneurs and foster competition in the innovative sector. At the same time, however, the entrepreneur's choice of project will be distorted whenever she produces for market entry. ${ }^{22}$ As shown in panel (i) of Figure 3, when profit tax rates are in the range $t \in\left[0, t^{C}\right)$, even risk-neutral entrepreneurs will choose projects that involve too little risk and fall short of maximizing the expected return from the investment $\left(p_{E}^{*}>\hat{p}\right)$. This effect arises from the imperfect loss offset that entrepreneurs face in case of project failure. We now turn to the welfare implications of this result.

\footnotetext{
${ }^{22}$ This is also true when a mixed strategy equilibrium results in Regime 2 , as a result of a coordination failure between incumbents. Recall our discussion at the end of Section 3.3.
} 


\subsection{Welfare effects of tax policy}

In this section we analyze how taxes impact expected welfare by affecting the R\&D project choice and the commercialization mode of the entrepreneur. To this end we measure welfare as the sum of aggregate industry profits, consumer surplus and tax revenue. In Regime 1, where the entrepreneur enters the market, the net reward is given by $\left(1-t^{e}\right)\left[p_{E} \Gamma\left(p_{E}\right)\right]-\left(1-p t^{e}\right) I$ in eq. (10). However the expected income loss for the entrepreneur that arises from the inability to deduct investment cost from tax in case the project fails is fully compensated by higher expected tax payments, $t^{e} p(\Gamma-I)$. Hence the sum of tax revenue and the entrepreneur's net reward equals the gross reward from the innovation, $p_{E} \Gamma\left(p_{E}\right)-I$.

In Regimes 2 and 3, where the innovation is sold to an incumbent, the personal income $\operatorname{tax} \tau$ is applied on the tax base $\left(v_{e}-I\right)$ and $\left(v_{i i}-I\right)$, respectively. Together with tax revenues, the gross reward is again $p_{E} \Gamma\left(p_{E}\right)-I$ in Regime 2 and $p_{S} \Gamma\left(p_{S}\right)-I$ in Regime 3. This yields the following expressions for expected welfare:

$$
E[W]= \begin{cases}p_{E}^{*} \Gamma\left(p_{E}^{*}\right)-I+n \pi(i)+C S(i) & \\ +p_{E}^{*}\{n[\pi(e)-\pi(i)]+C S(e)-C S(i)\} & \text { in R1 } \\ p_{E}^{*} \Gamma\left(p_{E}^{*}\right)-I+n \pi(i)+C S(i) & \text { in R2 } \\ p_{S}^{*} \Gamma\left(p_{S}^{*}\right)-I+n \pi(i)+C S(i) & \text { in R3 }\end{cases}
$$

In eq. (19), the expected welfare expression in Regime 1 accounts for the fact that market entry by the entrepreneur increases the number of firms from $n$ to $(n+1)$. This causes a decline in the incumbents' aggregate profits given by $n[\pi(e)-\pi(i)]<0$ and an increase in consumer surplus given by $C S(e)-C S(i)>0$. Thus the term in the second line of Regime 1 combines the externalities caused by the market entry of the entrepreneur. This term is labelled the aggregate business stealing effect by Mankiw and Whinston (1986) and it can be positive or negative, depending on the underlying olipopoly model. In a symmetric Cournot model with homogenous goods, the reduction in producer surplus dominates and the overall externality caused by market entry is negative. If firms' products are differentiated, however, the increase in consumer surplus from entry may dominate as consumers also value the addition of a new product.

We can now discuss the overall welfare effects of tax policy. If $n[\pi(e)-\pi(i)]+C S(e)-$ $C S(i)<0$ holds in Regime 1 , then market entry by the entrepreneur unambiguously reduces aggregate welfare, relative to the alternative of selling the innovation. Re- 
call that $p_{E} \Gamma\left(p_{E}\right)$ in Regimes 1 and 2 is below $p_{S} \Gamma\left(p_{S}\right)$ in Regime 3 , because the entrepreneur's project choice is distorted in the first two regimes, but not in the third [cf. eqs. (11) and (12)]. Hence a clear welfare ranking arises in this case with $E[W(R 1)]<E[W(R 2)]<E[W(R 3)]$. From Proposition 1, the optimal policy in this case would thus tax the entrepreneur's profits under market entry at a similar rate as the proceeds from the sale of the innovation to an incumbent firm.

In contrast, when $n[\pi(e)-\pi(i)]+C S(e)-C S(i)>0$ then a trade-off results for tax policy. There is now an argument to tax-discriminate in favour of entrepreneurial market entry, as this will benefit consumers due to increased competition, lower prices and higher output in the innovative market. At the same time, however, market entry by the entrepreneur will still imply a choice of project that involves too little risk and therefore does not maximize the expected benefits from the innovation. Thus, government policy towards small firms has to make a choice between the goals of competition policy on the one hand, and the fostering of 'breakthrough' inventions on the other.

So far we have followed the typical way of evaluating welfare in concentrated industries, which is built on the assumption that the policy under consideration does not affect other markets. As we have discussed in the introduction, however, one of the main objectives of supporting small, entrepreneurial firms is the belief that they create additional jobs. This objective is particularly relevant in countries suffering from inefficient labour markets and high unemployment. It is straightforward to incorporate this argument into our analysis, using the additional notation for sectoral production and employment introduced in Section 3.1. Recalling that the employment in firm $j$ is denoted by $l_{j}(m)$ and using symmetry, the expected sectoral employment under market entry is $E[L(e)]=(n+1)[l(e)+F]-p_{E}^{*} \Gamma\left(p_{E}^{*}\right)$. In contrast, expected employment under an entry-deterring sale in Regime 2 is $E[L(i)]=n l(i)+p_{E}^{*} \Gamma\left(p_{E}^{*}\right)$ and under a competitive sale in Regime 3 it is $E[L(i)]=n l(i)+F-p_{S}^{*} \Gamma\left(p_{S}^{*}\right)$.

To further explore these employment effects, suppose that firms produce with a constant returns to scale technology with $l_{j}(m)=q_{j}^{*}(m)+F_{j}$, where $q_{j}($.$) is firm j$ 's output. Recalling that labor is the only input in production, expected employment in the entrepreneurial firm under entry is $q^{*}(e)+F-p_{E}^{*} \Gamma\left(p_{E}^{*}\right)>0$ and total sectoral employment under entry is $E[L(e)]=(n+1)\left[q^{*}(e)+F\right]-p_{E}^{*} \Gamma\left(p_{E}^{*}\right)$. If the project is instead sold to an incumbent, there is no employment in the entrepreneurial firm and sectoral employ- 
ment is $E[L(i)]=n\left[q^{*}(i)+F\right]-p^{o p t} \Gamma\left(p^{o p t}\right)$ where $p^{o p t}=p_{E}^{*}$ in Regime 2 and $p^{o p t}=p_{S}^{*}$ in Regime 3. Introducing aggregate output $Q^{*}(e) \equiv(n+1) q^{*}(e)$ and $Q^{*}(i) \equiv n q^{*}(i)$ it then follows that:

$$
E[L(e)]-E[L(i)]=\left[Q^{*}(e)-Q^{*}(i)\right]+F+\left[p^{o p t} \Gamma\left(p^{o p t}\right)-p_{E}^{*} \Gamma\left(p_{E}^{*}\right)\right]>0 .
$$

The first term in this inequality captures that aggregate production rises when an additional firm enters the market and the second term results because the additional firm also demands additional labor for its fixed operations. Finally, the third term is zero in comparison to a sale in Regime 2 and positive in comparison to a sale in Regime 3, mirroring the fact that market entry creates fewer expected savings of labor used in the fixed operations as compared to a project sale in Regime 3. In sum, commercialization by entry therefore unambiguously increases employment, relative to either an entry-deterring or a competitive project sale. This is stated in the following proposition:

Proposition 3 When the technology exhibit constant returns to scale and the innovation affects only fixed costs, then commercializing the innovation via the market entry of the entrepreneur increases total employment in comparison to commercialization by sale, $E[L(e)]-E[L(i)]>0$.

In a setting where the employment effects summarized in Proposition 3 are more important than the costs of a distorted project choice, there is thus an argument that policymakers should indeed tax market entry more favorable, or grant specific subsidies to SMEs. This conclusion, however, hinges on the assumption that the innovation affects only fixed production costs. In the next section, we will see that results may be very different when the choice of the $R \& D$ projects affects variable production costs.

\section{$5 \quad$ Variable cost saving inventions}

In this section, we show that if more risky projects are associated with larger reductions in variable costs (or improvements in quality), consumers may unambiguously prefer commercialization by sale over commercialization by entry. For this purpose, we briefly discuss how the analysis in the different stages of the game changes when variable cost reductions are allowed for. 
Stage 4: Consider a situation where the invention reduces the variable cost, while fixed costs are ignored. Hence the gains from a more risky project in case of success are now given by larger variable cost savings for the possessor of the invention. Let the acquiring incumbent's product market profit for a successful invention be $\pi_{A}(i, p)$, where $p$ is the project choice in Stage 1. Similarly, let the entrepreneur's profit when entering be $\pi_{E}(e, p)$ and let a non-acquiring incumbent's profit be $\pi_{N A}(m, p)$. We then introduce

Assumption A3: (i) $\frac{d \pi_{A}(i, p)}{d p}<0, \frac{d \pi_{E}(e, p)}{d p}<0$, (ii) $\frac{d \pi_{N A}(m, p)}{d p}>0, m \in\{e, i\}$.

Assumption A.3 (i) states that the product market profit from a successful invention is smaller for the possessor (either the acquiring incumbent or the entrepreneur herself) when the riskiness of the project decreases. Assumption A.3 (ii) states that non-acquiring incumbents see their profits increasing when the possessor has a safer project, since rivals then face less fierce competition from the owner of the invention. These assumptions will, for instance, hold for a process innovation where a more risky innovation leads to a larger reduction in the marginal cost of selling and producing for the product market.

Stage 3: At this stage, it is again revealed whether the innovation turns out to be successful. We maintain Assumption A1 so that entry is only profitable if the project succeeds. Hence $\pi_{E}(e, p)-G \geq 0$, but $\pi_{E}(e, 0)-G=0$, where $\pi_{E}(e, p)$ is the profit of the entrepreneur under entry with project $p$ and $\pi_{E}(e, 0)$ is the profit with a failed project.

Stage 2: At the commercialization stage, the entrepreneur's reservation price defined in (6) becomes:

$$
v_{e}=\frac{(1-t)}{(1-\tau)}\left\{p\left[\pi_{E}(e, p)-G\right]-\frac{(\tau-p t)}{(1-t)} I\right\}
$$

The takeover valuation and the competitive valuations of an incumbent defined in (8) and (9) become

$$
v_{i e}=p\left[\pi_{A}(i, p)-\pi_{N A}(e, p)\right], \quad v_{i i}=p\left[\pi_{A}(i, p)-\pi_{N A}(i, p)\right]
$$

where again $v_{i e}>v_{i i}$ since $\pi_{N A}(e, p)<\pi_{N A}(i, p)$. From the latter inequality, it follows that the equilibrium commercialization mode can be solved by applying Lemma 1 . 
Stage 1: Turning to the entrepreneur's project choice, we assume that $p \pi_{E}(e, p)$ and $p\left[\pi_{A}(i, p)-\pi_{N A}(m, p)\right]$ are strictly concave in $p$, ensuring well-defined project choices. Introducing $E[\pi(m, p)] \equiv p \pi(m, p)$ as the expected value of the project and using Assumption A1, the first-order condition for the optimal project choice when innovating for entry or selling at the reservation price $S^{*}=v_{e}$ in Regimes 1 and 2 becomes:

$$
\frac{d E\left[\pi_{E}(e, p)\right]}{d p}=0 \Longrightarrow p_{E}^{*} \frac{d \pi_{E}\left(e, p_{E}^{*}\right)}{d p}=-\frac{t}{(1-t)} I .
$$

As in our benchmark model [see eq. (12)], the inability to deduct the investment costs from tax in case of failure will induce the investor to choose a project with too little risk, other things being equal.

When innovating for sale under bidding competition in Regime 3, receiving the sale price $S^{*}=v_{i i}$ [see eq. (11)], the optimal project choice is given by

$$
\frac{d E\left[\pi_{A}(i, p)\right]}{d p}-\frac{d E\left[\pi_{N A}(i, p)\right]}{d p}=\pi_{A}\left(i, p_{S}^{*}\right)+p_{S}^{*} \frac{d \pi_{A}\left(i, p_{S}^{*}\right)}{d p}-\pi_{N A}\left(i, p_{S}^{*}\right)-p_{S}^{*} \frac{d \pi_{N A}\left(i, p_{S}^{*}\right)}{d p}=0 .
$$

The optimal project choice in Regime 3 is again independent of the effective tax rate. There is, however, an important difference to our benchmark case. With variable cost reductions, an entrepreneur that chooses an optimal project for sale will not only consider how the expected product market profit of the acquirer is affected, but she will also take into account that choosing a safer project increases the expected profit for a non-acquirer (see Assumption A3). Since the incumbents' willingness to pay for the project is negatively affected by the profits of a non-acquirer [see eq. (21)], this gives a strategic incentive to the entrepreneur to choose a more risky project.

This strategic incentive is shown in the lower panel (ii) of Figure 4, where the slope of the marginal expected profit curve from a change in $p$ is always steeper in Regime 3 as compared to Regimes 1 and 2. For this reason the difference in the risk characteristics of the projects chosen in Regime 1 and 2 on the one hand and Regime 3 on the other is even larger than in our benchmark case.

\footnotetext{
$* * * * * * * * *$ Figure 4 about here $* * * * * * * * * *$
}

The effects of tax policy on consumers. Let us now examine how effective tax rates affect consumers through the entrepreneur's choice of project and the mode of commercialization. Maintaining Assumption A2, we proceed as in Section 4 and define 
reduced-form valuations $v_{r}(t) \equiv v_{r}\left(p^{o p t}(t)\right)$. Taking the total derivative in effective taxes $t$ and applying the envelope theorem, it is straightforward to show that Propositions 1 and 2 are also fulfilled when more risky projects are associated with larger variable cost reductions.

Consider now the upper panel (i) of Figure 4. Let $\overline{C S}$ be the consumer surplus when the invention has failed. The expected consumer surplus under innovation by entry and under innovation by sale is then $E[C S(e, p)] \equiv p C S(e, p)+(1-p) \overline{C S}$ and $E[C S(i, p)] \equiv$ $p C S(i, p)+(1-p) \overline{C S}$, respectively. For the same project $p$, innovation by entry always gives a higher expected consumer surplus since $C S(e, p)>C S(i, p)$ from the concentration effect of an acquisition. Assume that the expected consumer surplus is strictly concave in $p$, so that there exist optimal projects $p_{S}^{C S}=\arg \max _{p}[p C S(p, i)+(1-p) \bar{C} S]$ and $p_{E}^{C S}=\arg \max _{p}[p C S(p, e)+(1-p) \bar{C} S]$ from the perspective of consumers. Note that, because of imperfect competition in the product market, the interests of producers and consumers are generally not aligned in our model. Regardless of entry mode, the entrepreneur will therefore not choose a project that maximizes the expected consumer surplus, so that in general $p_{E}^{*} \neq p_{E}^{C S}$ and $p_{S}^{*} \neq p_{S}^{C S}$ holds.

Suppose that we start from a high effective corporate tax rate for the entrepreneur, $t>t^{C}$. From Proposition 1, this implies that the entrepreneur will choose commercialization by sale at the sales price $S^{*}=v_{i i}$. This yields an expected consumer surplus of $E\left[C S\left(e, p_{S}^{*}\right)\right]$, as shown by point $S$ in Figure 4 (i). Suppose then that the effective tax rate is reduced to $t_{1}<t^{C}$ so that the entrepreneur chooses instead commercialization by entry. With the new effective tax rate $t_{1}$ the entrepreneur will choose an overly safe project under market entry, due to the incomplete loss offset provisions of the corporate tax code. This project choice, however, yields only limited reductions in variable costs, and hence consumer prices, in case it succeeds. A comparison of the points $S$ and $E_{1}$ in Figure 4 (i) reveals that the expected consumer surplus will be lower under market entry than under sale, $E\left[C S\left(e, p_{E_{1}}^{*}\right)\right]<E\left[C S\left(i, p_{S}^{*}\right)\right]$, even though the number of competitors is higher with market entry by the entrepreneur.

In this case the interests of consumers will be best served when the entrepreneur sells the innovation to an incumbent firm in Regime 3 and chooses a project that minimizes the expected variable costs of production. Moreover, commercialization by sale may also be preferred from the perspective of maximizing total employment. The reason is that lower consumer prices are generally associated with higher total output, resulting in 
higher employment if the expansion in output dominates the labor saving effects of new technologies. The optimal policy would thus be to tax the entrepreneur's profits under market entry and the proceeds from the sale of the innovation at roughly equal tax rates, so as to preserve neutrality for the entrepreneurial decision on how to commercialize the innovation.

\section{Discussion and further extensions}

In this section, we discuss our results further by introducing some other extensions or modifications of our benchmark model.

\subsection{Stage 0: Entrepreneurial choice of effort}

An important aspect of entrepreneurial innovation is that a substantial share of the initial investment may consist of effort put in by the entrepreneur. We incorporate this aspect by introducing a zero stage of the game where the entrepreneur chooses an endogenous level of effort, denoted by $\rho$, in order to generate a basic innovative idea. We then study how taxes affect this choice variable.

The entrepreneur's effort level $\rho$ determines the probability of succeeding with a basic invention that is necessary for being able to start an R\&D project in Stage 1. For simplicity, assume that the probability of succeeding with a basic invention is simply the effort, i.e. $\rho \in[0,1]$, and that effort is associated with an increasing and convex cost $y(\rho)$, i.e. $y^{\prime}(\rho)>0$, and $y^{\prime \prime}(\rho)>0$. Efforts are not deductible when paying taxes. Then, let $\Omega^{*}\left(p^{o p t}\right)$ be the reduced-form expected profit given from equation (10). Define $\Pi=\rho \Omega^{*}\left(p^{o p t}\right)-y(\rho)$ as the expected net profit of a basic invention. The optimal effort level $\rho^{*}$ is then given from:

$$
\frac{d \Pi}{d \rho}=\Omega^{*}\left(p^{o p t}\right)-y^{\prime}\left(\rho^{*}\right)=0,
$$

with the associated second-order condition $d^{2} \Pi / d \rho^{2}=-y^{\prime \prime}(\rho)<0$.

Applying the implicit function theorem in (24), we can state the following lemma:

Lemma 2 The equilibrium effort by the entrepreneur in stage $0, \rho^{*}$, and hence the probability of succeeding with a basic invention, increases in the net reward for the invention, i.e. $d \rho^{*} / d \Omega^{*}\left(p^{o p t}\right)>0$. 
To determine the effects of taxes on the entrepreneur's effort level, we start with the effective corporate tax rate $t$. Note from eq. (10) that the reduced-form net reward is $\Omega^{*}\left(p_{E}^{*}\right)=(1-\tau)\left[v_{e}\left(p_{E}^{*}\right)-I\right]$ for $t \in\left[0, t^{C}\right]$, and $\Omega^{*}\left(p_{S}^{*}\right)=(1-\tau)\left[v_{i i}\left(p_{S}^{*}\right)-I\right]$ for $t>t^{C}$. The reservation price is decreasing in corporate taxes from eq. (17), whereas the competitive valuation of incumbents is independent of corporate taxes from eq. (16). Thus, it follows that an increase in corporate tax only decreases the incentives to provide effort when corporate taxes are so low that an equilibrium in Regime 1 or 2 results. In contrast, if corporate taxes are sufficiently high so that a sale takes place under bidding competition (Regime 3), the net reward is independent of corporate taxes. This is illustrated in Figure 5.

$* * * * * * * * *$ Figure 5 about here $* * * * * * * * * *$

Turning to the personal income tax $\tau$, differentiating the net reward $\Omega^{*}\left(p_{l}^{*}\right)$ in $(10)$ with respect to $\tau$, using (6) and once more noting that indirect effects through the choice of $p$ are absent in all regimes yields

$$
\begin{gathered}
\frac{d \Omega^{*}\left(p_{E}^{*}\right)}{d \tau}=0 \quad \text { for } t \in\left[0, t^{C}\right] \\
\frac{d \Omega^{*}\left(p_{S}^{*}\right)}{d \tau}=\frac{\partial \Omega^{*}\left(p_{S}^{*}\right)}{\partial \tau}=-\left[v_{i i}\left(p_{S}^{*}\right)-I\right]<0 \text { for } t>t^{C} .
\end{gathered}
$$

Hence, an increase in the personal income tax reduces the net reward for the innovation in Regime 3, but not in Regimes 1 and 2. Using Lemma 2, we can then summarize our results as follows:

Proposition 4 Increased corporate taxes (in Regimes 1 and 2) and increased personal income taxes (in Regime 3) reduce the effort to create innovative ideas.

Proposition 4 shows that the disincentive effects of a particular tax on entrepreneurial effort will generally depend on the commercialization mode in our model. This complements existing results in the literature which have emphasized the effort-reducing effects of capital gains taxes, in particular, but not in a setting with an endogenous commercialization choice (e.g. Keuschnigg and Nielsen, 2004). 


\subsection{Post uncertainty sale and multi-firm licensing}

As illustrated in Figure 1, our benchmark model assumes that the entrepreneur can only sell the invention in Stage 2. Hence, we have ruled out the option for the entrepreneur to sell the invention after the uncertainty has been lifted in Stage 3. In this section, we demonstrate that such post-uncertainty sales will not occur in equilibrium.

If the project is revealed to be a success at the beginning of Stage 3, this information is private and cannot be credibly revealed to incumbents. The superiority of the entrepreneur's cost structure can only be verified in Stage 4, when the profits from product market interaction become public information through accounting laws and accounting standards. We proceed to show that if an acquisition has not occurred in Stage 2, there will not be an acquisition post-uncertainty in Stage 3. We assume that the acquisition auction in Stage 3 is once more a first-price perfect information auction with externalities and solve for Nash equilibria in undominated pure strategies. Using Assumption A1, the entrepreneur's net gain from selling the invention at price $S$ over the alternative of market entry is now

$$
\Delta_{e}(S)=\underbrace{S-\tau(S-I)}_{\text {Net profit from sale }}-\{\underbrace{\Gamma\left(p^{*}\right)-t\left[\Gamma\left(p^{*}\right)-I\right]}_{\text {Net expected profit from entry }}\} .
$$

Solving for $\Delta_{e}(S)=0$, we obtain the reservation price post-uncertainty in Stage 3:

$$
w_{e}(p)=\frac{(1-t)}{(1-\tau)}\left\{\Gamma\left(p^{*}\right)-\frac{(\tau-t)}{(1-t)} I\right\}
$$

Comparing (28) and (6) shows that $w_{e}(p)>v_{e}(p)$ : the reservation price of the entrepreneur has risen because the success probability is one from her point of view. However, incumbents cannot infer the quality of the project so that their valuations remain at $v_{i e}$ and $v_{i i}$, as defined in (8) and (9). If no acquisition occurred in Stage 2, this implies that $v_{e}>v_{i e}>v_{i i}$. But then, an acquisition in Stage 3 cannot be profitable from $w_{e}(p)>v_{e}$.

An issue that also arises in this context is multi-firm licensing. Multi-firm licensing seems not to be an option before uncertainty is revealed, since no "product" can then be licensed, but it may become a relevant issue post-uncertainty. There are, however, several reason why multi-firm licensing might not be an optimal strategy, even in the case where inventions reduce only fixed costs. 
First, in many cases, the 'innovation' consists of a combination of assets in terms of capital, intellectual capital, and human capital, which cannot be used by many firms simultaneously. Multi-firm licensing is then not an option. ${ }^{23}$ Second, if the licensee and the licensor need to undertake post-licensing investments, free riding problems will likely be increased if there are many licensees. Third, if asymmetric information is present, the paradox of disclosure (Arrow, 1962) might arise. The willingness-to-pay of potential buyers depends then on their knowledge of the idea. Disclosure increases the buyer's valuation but reduces the inventor's bargaining power. Potential buyers can claim that an idea was known, expropriating innovators once they have disclosed their invention. The disclosure problem can be ameliorated by not licensing to all firms in the market. When many partners are potentially available, innovators can credibly threaten to pursue their idea with a third party when conducting bilateral negotiations with a particular established firm. The start-up's ability to threaten pervasive disclosure increases its bargaining power and so reduces the degree of expropriation (Anton and Yao, 1994, 1995).

\subsection{Innovation for sale and incorporation}

We have assumed that entrepreneurs that innovate for sale never incorporate. In practice, we observe that some entrepreneurs incorporate before selling their invention. What would be the effect of allowing entrepreneurs that innovate for sale to incorporate, in order to face a lower tax rate?

For analytical simplicity, we focus on the extreme case where tax rates are identical when innovating for market entry or for sale, i.e. $t=\tau .{ }^{24}$ In order to still have a tradeoff between market entry and sale in this case, we add a tax-deductible transaction cost $T$ for incumbents when acquiring. This cost could correspond to, for instance, legal fees

\footnotetext{
${ }^{23}$ Indeed, we observe many cases where small, innovative firms are acquired by a single, large incumbent. An example is Cisco's acquisition of Cerent in 1999 at the price of $\$ 6.9$ billion.

${ }^{24}$ Hence the specification here ignores the fact that some government subsidies for SMEs are only available when entrepreneurs actually enter the market.
} 
and due diligence. An incumbent's net gain then becomes:

$$
\begin{aligned}
\Delta_{i m}(S)= & \underbrace{p\left(1-t^{i}\right)[\underbrace{\pi(i)-(\bar{F}-\Gamma(p))-S}_{\text {Profit from buying }}-T-\underbrace{(\pi(m)-\bar{F})}_{\text {Net expected value from an unsuccessful innovation }}]}_{\text {Net expected value from a successful innovation }} \\
& \underbrace{+(1-p)\left(1-t^{i}\right)[\underbrace{\pi(i)-\bar{F}-S}-T-\underbrace{(\pi(i)}_{(i)-\bar{F})}]}_{\text {Profit from buying }}] \\
= & \underbrace{}_{\left(1-t^{i}\right)\{-S-T+p \Gamma(p)+p[\pi(i)-\pi(m)]\} .} .
\end{aligned}
$$

Then, use that an incumbent firm's valuation is $v_{i m} \equiv \max S$, s.t $\Delta_{i m}(S) \geq 0$. Solving for $\Delta_{i m}(S)=0$ gives $v_{i m}=p \Gamma(p)+p[\pi(i)-\pi(m)]-T$ as the maximum price $S$ at which an incumbent firm is willing to buy the entrepreneur's invention. The takeover valuation and the competition valuation are

$$
v_{i e}(p)=p \Gamma(p)+p[\pi(i)-\pi(e)]-T, \quad v_{i i}(p)=p \Gamma(p)-T .
$$

Note that the fixed cost $T$ has no effect on the optimal project choices in eq. (15). Hence, the entrepreneur's reservation price is once more given by (6), which simplifies to

$$
\left.v_{e}(p)\right|_{t=\tau}=p \Gamma-\frac{t(1-p)}{(1-t)} I .
$$

It then directly follows from eqs. (30)-(31) that if transaction costs $T$ become sufficiently large, the reservation price of the entrepreneur will be higher than incumbents' valuations, even if $t=\tau$. This holds in equilibrium when we incorporate optimal project choices, which are unaffected by transaction costs and given in eq. (15) ${ }^{25}$ Hence, when the entrepreneur produces for entry, she will still choose an inefficient project that bears too little risk, as a result of incomplete loss offset provisions.

\subsection{Venture capitalists and financial partners}

Our benchmark analysis has assumed that the entrepreneur is not able to obtain tax rebates for the investment costs incurred when she attempts to enter the market herself, but the project fails. These loss offset restrictions imply that the entrepreneur

\footnotetext{
${ }^{25}$ This can be illustrated in panel (iii) of Figure 3, where transaction costs would merely shift down the locus of the takeover valuation $v_{i e}\left(p^{o p t}\right)$ and the competitive valuation $v_{i i}\left(p^{o p t}\right)$.
} 
could gain from the co-operation with partners who have other incomes to deduct the losses against. Thus, the distortion to the choice of project could be avoided if the entrepreneur used a noncorporate flow-through entity in Stage 1, where the investment cost $I$ is incurred. Then the costs could be deducted as long as at least one partner has sufficient positive income. This is likely to be the case, in particular, if the other party is a financial partner.

These types of partnerships are, however, associated with severe adverse selection and moral hazard problems. Hence financial partners, where they exist, almost always involve a highly specialized venture capitalist. Indeed, only few projects are venture capital backed in most countries. Even in the United States, where the venture capital market is by far the largest, only 14,000 portfolio companies worldwide received venture capital over a 30-year period from 1975 to 2005 (Lerner, 2010). Total venture capital investments in the United States amounted to 28.8 billion US- $\$$ in 2008 , corresponding to 0.20 percent of this country's GDP. ${ }^{26}$ In Europe, the share of venture capital investments in GDP is much lower, equalling 0.07 percent of national GDP in Sweden, 0.05 percent in the United Kingdom and 0.03 percent of GDP in Germany (EFI, 2011, p. 19).

Moreover, even for start-up firms backed by venture capital (VC), the possibility to deduct losses for tax purposes is far from complete. On the one hand, entrepreneurs usually retain a substantial ownership share in the VC-backed company, in order to mitigate the moral hazard problems inherent in the relationship with the venture capitalist (Keuschnigg and Nielsen, 2002, 2004). This implies, however, that loss offset restrictions will still apply for the ownership share of the entrepreneur. In addition, some countries' tax laws also restrict the tax deduction of losses for venture capitalists. In Germany, for example, unused tax losses cannot be transferred when the venture capitalist sells her shares in the company - for example to another VC firm, which specializes in financing a different development phase of the start-up. These restrictive tax provisions are widely believed to hinder VC financing, but also the establishment and growth of innovative companies in Germany (EFI, 2011, p. 19).

In sum, bringing venture capital financing into the picture and accounting for its relative importance will introduce some qualifications to our assumption that an entrepreneur producing for market entry is not able to obtain any tax rebates for losses incurred

\footnotetext{
${ }^{26}$ See "Investment funding rose 5 percent in 2008", VentureBeat, 18 February 2009.
} 
in the investment phase. However, this extension will clearly not overturn our basic argument that loss offset restrictions are more severe when the entrepreneur produces for market entry, as opposed to selling her innovation to an incumbent firm.

\section{Conclusion}

In this paper we have focused on two important decision margins of entrepreneurs that have received little analysis so far in a context of public policy. These are the decision of the entrepreneur to choose between projects with different risk and return characteristics, and her decision of how to commercialize the innovation. Our analysis has shown that government policies to support small, technology-intensive businesses by means of various subsidy programs will promote market entry by entrepreneurs over the alternative of selling out the innovation to incumbent firms. At the same time, however, the entrepreneur will choose R\&D projects involving suboptimally low levels of risk and expected return. This points to a basic trade-off for governments between a policy that promotes market entry and firm growth for start-up firms in technologyintensive markets, and the goal of fostering 'breakthrough' innovations that maximize expected cost reductions.

Our analysis has also indicated that the welfare implications from this trade-off may depend strongly on the precise effects that innovations have on the firms' cost structure. If innovations reduce mostly fixed costs, fostering market entry by SMEs will increase aggregate employment and consumer surplus and may therefore be an attractive policy, despite the induced distortion of R\&D choices. If, however, innovations have a substantial effect on the marginal cost of producing output, then distorting the entrepreneur's project choice under market entry has far more severe implications. In this case, it is possible that a subsidy-induced market entry by SMEs reduces both output and employment, in addition to distorting the choice of the innovation project. In this case consumers would be unambiguously better off if the subsidies to SMEs' market entry were eliminated and the entrepreneur sold the innovation to an incumbent firm.

Our results can be contrasted with existing policies to support entrepreneurship in the European Union and elsewhere. The Small Business Act for Europe (European Commission, 2008, 2011), for example, simultaneously aims at fostering risky innovations and employment growth through the promotion of SMEs. Our benchmark case, where 
innovations reduce only fixed costs, has shown that these two policy goals may be mutually incompatible when the interaction between the entrepreneur's project choice and the choice of commercialization mode is explicitly analyzed. Moreover, when innovations reduce variable production costs, a policy of supporting market entry by entrepreneurs may even run counter to both the employment and the innovation goals set out in the Small Business Act. What would be needed instead in this case is a tax and subsidy policy that is neutral with respect to the entrepreneur's choice of retaining or selling the firm. Another part of the appropriate policy package would be to improve the legal framework and reduce the transaction costs for sales to incumbent firms, so as to ensure an effective bidding competition for target firms and their patents.

Our analysis has taken as given that entrepreneurs are unable to claim tax rebates for the losses incurred in the case of project failure. One might therefore ask whether it is possible, or even attractive, to fully eliminate the asymmetry in the tax treatment of profits and losses in existing tax systems. This would imply, however, that tax rebates must be granted for investment costs, even if there is no offsetting positive income in any period. Hence the overall tax payments of a firm over its entire life cycle could become negative, resulting in a transfer from the tax authorities to the entrepreneur. It seems obvious that such a tax provision, if introduced, would be highly susceptible to abuse and fraud, even if it were explicitly confined to enterprises below a welldefined size threshold. Moreover, a selective policy where full offset provisions only apply to SMEs would add to the tax privileges that small businesses already enjoy under current tax rules in many countries, and which have been severely criticized as distorting competition in the business sector (see Mirrlees et al., 2011). For these reasons we believe that the second-best framework with imperfect loss offset which underlies our analysis will remain the relevant setting in which to analyze public policy towards entrepreneurs.

In addition to its normative implications, our analysis also leads to several hypotheses that can be tested empirically. As incentive schemes for small businesses have proliferated and corporate tax rates for incorporated start-ups have fallen sharply in many countries, this has led to a rising tax/subsidy advantage for market entry by entrepreneurs over the alternative of project sale. According to our analysis, these developments should have led to a rising share of innovations that are commercialized by the market entry of entrepreneurs and at the same time should have induced less risky, and also less efficient, innovation projects. 
In concluding, we emphasize that our analysis is but a first step towards a more comprehensive study of the effects of public policies on the market for entrepreneurial innovations. A first limitation of our analysis is that we have not been able to derive optimal policies towards small businesses endogenously, due to the complex decision structure of our model. A further restriction is that our analysis has been static in nature, even though a core reason for the support of entrepreneurial innovations is their growthpromoting effect. Finally, entrepreneurial investment sometimes takes place within a highly complex framework of contractual arrangements between innovators, banks and venture capitalists, where incentives for all agents can be distorted. For instance, heavy reliance on debt financing can lead to excessive risk-taking by entrepreneurs, counteracting the distortion that arises from limited loss offset opportunities in the present paper. These extensions seem to be promising areas for future research.

\section{Appendix: Proof of Lemma 1}

First, note that $b_{i} \geq \max v_{i l}, l=\{\mathrm{e}, \mathrm{i}\}$ is a weakly dominated strategy, since no incumbent will post a bid equal toor above its maximum valuation of obtaining the invention and that firm $e$ will accept a bid iff $b_{i}>v_{e}$.

Regime 1: Consider equilibrium candidate $b^{*}=\left(b_{1}^{*}, b_{2}^{*}, \ldots, n o\right)$, where $b_{j}^{*}<v_{e} \forall j \in J$. It then directly follows that no firm has an incentive to deviate and thus, $b^{*}$ is a Nash equilibrium.

Then, note that the entrepreneur will accept a bid iff $b_{j} \geq v_{e}$. But $b_{j} \geq v_{e}$ is a weakly dominated bid in these intervals, since $v_{e}>\max \left\{v_{i i}, v_{i e}\right\}$. Thus, the assets will not be sold in these intervals.

Regime 2: Consider equilibrium candidate $b^{*}=\left(b_{1}^{*}, b_{2}^{*}, \ldots, y e s\right)$. Then, $b_{w}^{*}>v_{e}$ is not an equilibrium since firm $w$ would then benefit from deviating to $b_{w}=v_{e}$. Further, $b_{w}^{*}<v_{e}$ is not an equilibrium, since the entrepreneur would then not accept any bid. If $b_{w}^{*}=v_{e}-\varepsilon$, then firm $w$ has no incentive to deviate. By deviating to $b_{j}^{\prime} \leq b_{w}^{*}$, firm $j$ 's payoff does not change $(j \neq w, e)$. By deviating to $b_{j}^{\prime}>b_{w}^{*}$, firm $j$ 's payoff decreases since it must pay a price above its willingness to pay $v_{i i}$. Accordingly, firm $j$ has no incentive to deviate. By deviating to no, the entrepreneur's payoff decreases since it foregoes a selling price above its valuation $v_{e}$. Accordingly, the entrepreneur has no incentive to deviate and thus, $b^{*}$ is a Nash equilibrium. 
Let $b=\left(b_{1},,, b_{n}\right.$, yes $)$ be a Nash equilibrium. If $b_{w} \geq v_{i i}$, then firm $w$ will have the incentive to deviate to $b^{\prime}=b_{w}-\varepsilon$. If $b_{w}<v_{i i}$, the entrepreneur will have the incentive to deviate to no, which contradicts the assumption that $b$ is a Nash equilibrium.

Let $b=\left(b_{1}, \ldots, b_{n}, n o\right)$ be a Nash equilibrium. The entrepreneur will then say no iff $b_{h} \leq v_{e}$. But incumbent $j \neq d$ will have the incentive to deviate to $b^{\prime}=v_{e}+\varepsilon$ in Stage 1 , since $v_{i e}>v_{e}$. This contradicts the assumption that $b$ is a Nash equilibrium.

Regime 3: Consider equilibrium candidate $\mathbf{b}^{*}=\left(b_{1}^{*}, b_{2}^{*}, \ldots\right.$, yes $)$. Then, $b_{w}^{*} \geq v_{i i}$ is a weakly dominated strategy. Also $b_{w}^{*}<v_{i i}-\varepsilon$ is not an equilibrium since firm $j \neq w, e$ then benefits from deviating to $b_{j}=b_{w}^{*}+\varepsilon$, since it will then obtain the assets and pay a price lower than its valuation of obtaining them. If $b_{w}^{*}=v_{i i}-\varepsilon$, and $b_{s}^{*} \in$ $\left[v_{i i}-\varepsilon, v_{i i}-2 \varepsilon\right]$, then no incumbent has an incentive to deviate. By deviating to no, the entrepreneur's payoff decreases, as she foregoes a selling price exceeding her entry valuation $v_{e}$. Accordingly, the entrepreneur has no incentive to deviate and thus, $b^{*}$ is a Nash equilibrium.

Let $b=\left(b_{1}, \ldots, b_{n}, n o\right)$ be a Nash equilibrium. The entrepreneur will then say no iff $b_{h} \leq v_{e}$. But incumbent $j \neq e$ will then have the incentive to deviate to $b^{\prime}=v_{e}+\varepsilon$ in Stage 1 , since $v_{i e}>v_{e}$. This contradicts the assumption that $\mathbf{b}$ is a Nash equilibrium. 


\section{Literature}

Acs, Z.J., Audretsch D.B. (2005). Entrepreneurship, innovation and technological change. Foundations and Trends in Entrepreneurship 1, 149-195.

Altshuler, R., Auerbach, A.J. (1990). The significance of tax law asymmetries: An empirical investigation. Quarterly Journal of Economics 105, 61-86.

Anton, J.J., Yao, D.A. (1994), Expropriation and inventions: Appropriable rents in the absence of property rights. American Economic Review 84, 190-209.

Anton, J.J., Yao, D.A. (1995). Start-ups, spin-offs, and internal projects. Journal of Law, Economics \& Organization 11, 362-378.

Arrow, K.J. (1962). Economic welfare and the allocation of resources for invention. In: The rate and direction of inventive activity. Princeton: Princeton University Press, 609-625.

Asoni, A., Sanandaji, T. (2009). Taxation and the quality and quantity of entrepreneurship. INF Working Paper No. 813. Research Institute of Industrial Economics, Stockholm.

Auerbach, A.J. (2006). Why have corporate tax revenues declined? Another look. NBER Working Paper No. 12463. Cambridge, Mass.

Baumol, W.J. (2002). The free-market innovation machine: Analyzing the growth miracle of capitalism. Princeton: Princeton University Press.

Bhattacharya, S., Mookherjee, D. (1986). Portfolio choice in research and development. RAND Journal of Economics 17, 594-605.

Bianchi, M., Henrekson, M. (2005). Is neoclassical economics still entrepreneurless? Kyklos 58, 353-377.

Blonigen, B.A., Taylor, C.T. (2000). R\&D intensity and acquisitions in hightechnology industries: Evidence from the US electronic and electrical equipment industries. Journal of Industrial Economics 48, 47-70.

Bloom, N., Griffith, R., Van Reenen, J. (2002). Do R\&D tax credits work? Evidence from a panel of countries 1979-1997. Journal of Public Economics 85, 1-31. 
Cabral, L. (2003). R\&D competition when firms choose variance. Journal of Economics \& Management Strategy 12, 139-150.

Cullen, J.B., Gordon, R.H. (2007). Taxes and entrepreneurial risk-taking: Theory and evidence for the U.S. Journal of Public Economics 91, 1479-1505.

De Mooij, R., Nicodème, G. (2008). Corporate tax policy and incorporation in the EU. International Tax and Public Finance 15, 478-498.

Devereux, M.P., Lockwood, B., Redoano, M. (2008). Do countries compete over corporate tax rates? Journal of Public Economics 92, 1210-1235.

Domar, E.D., Musgrave, R.A. (1944). Proportional income taxation and risk-taking. Quarterly Journal of Economics 58, 388-422.

EFI (Expert Commission for Research and Innovation in Germany) (2011). Report 2011. http://www.e-fi.de/fileadmin/Gutachten/EFI_2011_en_final.pdf (English version).

Egger, P., Keuschnigg, C., Winner, H. (2009). Incorporation and taxation: Theory and firm-level evidence. CESifo Working Paper No. 2685, Munich.

Ernst, C., Spengel, C. (2011). Taxation, R\&D tax incentives and patent application in Europe. ZEW Discussion Paper No. 11-024, Mannheim.

European Commission (2008). Think small first. A "Small Business Act" for Europe. Communication COM (2008) 394. Brussels. http://ec.europa.eu/enterprise/policies/sme/small-business-act/index_en.htm

European Commission (2011). Review of the "Small Business Ac t for Europe". Communication COM (2011), 78. Brussels.

Färnstrand Damsgaard, E., Norbäck, P.-J., Persson, L., Vasconcelos, H. (2010). When do independent innovators make the break-through inventions? Mimeo, Research Institute of Industrial Economics, Stockholm.

Fuest, C., Huber, B., Nielsen, S.B. (2002). Why is the corporate tax rate lower than the personal tax rate? The role of new firms. Journal of Public Economics 8\%, $157-174$. 
Gentry, W.M., Hubbard, R.G. (2000). Tax policy and entrepreneurial entry. American Economic Review 90, 283-287.

Gilbert, R. (2006). Looking for Mr. Schumpeter: Where are we in the competitioninnovation debate? In: Jaffe, A.B., Lerner, J. and Stern, S. (eds.), Innovation Policy and the Economy, Vol. 6. MIT Press, Cambridge and London, 159-215.

Giuri, P., Mariani, M., Brusoni, S., Crespi, G., Francoz, D., Gambardella, A., BarciaFontes, W., Geuna, A., Gonzales, R., Harhoff, D., Hoisl, K., Le Bas, Ch., Luzzi, A., Magazzini, L., Nesta, L., ,Nomaler, Ö., Palomeras, N., Patel, P., Romanelli, M., Verspagen, B. (2007). Inventors and invention processes in Europe: Results from the PatVal-EU survey. Research Policy 36, 1107-1127.

Gordon, R.H. (1998). Can high personal income taxes encourage entrepreneurial activity? IMF Staff Papers 45, 49-80.

Gromb, D., Scharfstein, D. (2002). Entrepreneurship in equilibrium. NBER Working Paper 9001, Cambridge, Mass.

Henkel, J., Rønde, T., Wagner, M. (2010). And the winner is - acquired: Entrepreneurship as a contest with acquisitions as the prize. CEPR Discussion Paper No. 8147, London.

Henrekson, M., Johansson, D. (2010). Gazelles as job creators: a survey and interpretation of the evidence. Small Business Economics 35, 227-244.

Henrekson, M., Sanandaji, T. (2011). Taxing entrepreneurial income. Small Business Economics, forthcoming.

Keuschnigg, C., Nielsen, S.B. (2002). Tax policy, venture capital, and entrepreneurship. Journal of Public Economics 8\%, 175-203.

Keuschnigg, C., Nielsen, S.B. (2004). Start-ups, venture capitalists, and the capital gains tax. Journal of Public Economics 88, 1011-1042.

Lerner, J. (1999). The government as venture capitalist: The long-run impact of the SBIR program. Journal of Public Economics 72, 285-318.

Lerner, J. (2010). Geography, venture capital, and public policy. Rappaport Institute and Taubman Center Policy Briefs. March 2010. 
Mankiw, N.G., Whinston, M.D. (1986). Free entry and social inefficiency. RAND Journal of Economics 17, 48-58.

Mirrlees, J., Adam, S., Besley, T., Blundell, R., Bond, S., Chote, R., Gammie, M., Johnson, P., Myles, G., Poterba, J. (2011). Small Business Taxation. In: Tax by Design: The Mirrlees Review, 451-469. Oxford University Press.

OECD (1999). OECD economic surveys: Austria. Paris.

OECD (2007). Science, technology and industry scoreboard. Paris.

OECD (2010a). SMEs, entrepreneurship and innovation, Paris.

OECD (2010b). OECD tax database. www.oecd.org/ctp/taxdatabase.

Reinganum, J. (1989). The timing of innovation: Research, development, and diffusion. In: Schmalensee, R. and Willig, R. (eds.) Handbook of Industrial Organization. Elsevier, Amsterdam, 849-908.

Rosen, R. (1991). Research and development with asymmetric firm sizes. RAND Journal of Economics 22, 411-429.

Scherer, F.M., Ross, D. (1990). Industrial market structure and economic performance. Houghton Mifflin.

Serrano, C. (2010). The dynamics of the transfer and renewal of patents. RAND Journal of Economics 41, 686-708.

Tillväxtanalys (2010). Follow up of the newly established enterprises in 2005 - three years after the start. Statistik 2010:2, Sweden. www.tillvaxtanalys.se/tua/export/ sv/filer/statistik/nyforetagande/Uppfoeljning_3_xr_nystartade_foretag_2005.pdf 